\title{
Remission strategy in type 2 diabetes mellitus - a paradigm shift in the management of newly diagnosed patients
}

\author{
Prasad Katulanda ${ }^{1,2,3}$, MDSA Dilrukshi ${ }^{2}$, Vithiya Ratnasamy ${ }^{2}$ \\ ${ }^{1}$ Diabetic Research Unit, Faculty of Medicine University of Colombo, Sri Lanka \\ ${ }^{2}$ University Medical Unit, National Hospital of Sri Lanka \\ ${ }^{3}$ Harris Manchester College, University of Oxford, UK
}

Copyright: This is an open-access article distributed under the terms of the Creative Commons Attribution License, which permits unrestricted use, distribution, and reproduction in any medium, provided the original author and source are credited (CC BY 4.0)

Correspondence email: prasad.katulanda@yahoo.com

\section{Introduction}

Type 2 diabetes (T2DM) is a chronic, complex metabolic disease characterized by two main pathophysiological defects namely; insulin resistance and beta cell dysfunction which does not occur at once (1). Insulin resistance is defined as target cell resistance to the activity of insulin and beta cell dysfunction indicates insufficient secretion of insulin by the pancreatic beta cells to maintain normoglycaemia. The natural history of T2DM is characterised by progressive deterioration of beta cell function overtime. This pathological process is considered to be unabated by the life style and existing pharmacological interventions informed by the standard existing clinical guidelines (2).

Because of the progressive nature, the management of T2DM requires continuous medical care with increasingly complex therapeutic regimens. Current standards of care acknowledge that management of this inevitably progressive disease involve sequential addition of oral hypoglycaemic agent's overtime, followed by insulin therapy when the glycaemic control cannot be achieved without exogenous insulin supplementation due to near complete failure of pancreatic beta cell function.

The aforementioned practice of management of diabetes is characterized by 'treatment for failure' approach which is distinct from management of most of the other diseases, of which goals of management is cure. However, researchers in the field have not yet given up the uphill battle of defeating diabetes completely ie 'finding a cure'. There is an emerging evidence regarding the possibility of reversal or regression of diabetes in a majority of patients with T2DM especially the new onset.
Current understanding of pathophysiology of type 2 diabetes

As mentioned above, the natural history of T2DM shows inexorable progression despite diet, exercise and medical therapy. In the UKPDS study, among 4075 patients newly diagnosed as having type 2 diabetes who were managed with monotherapy of diet, metformin, sulfonylurea or insulin showed majority had progressive deterioration of glycaemic control with only $25 \%$ achieving the glycaemic control at 9 years with monotherapy (2). Similar findings were shown with sulfonylurea in ADOPT trial (3).

The two major pathological factors causing type 2 diabetes namely, insulin resistance and beta cell dysfunction are recognised to have different time courses rather than occurring simultaneously according to the current understanding (1). Insulin signalling defects (4), glucose transporter defects(5) and lipotoxicity (6) may be driving insulin resistance in skeletal muscles, liver and pancreas, whereas amyloid deposition in the islets (7), oxidative stress (8), excess fatty acid (9), or dysfunction of incretin effect (10) are attributed as causes of beta cell dysfunction.

\section{Insulin resistance in muscles}

Insulin resistance in skeletal muscles is the earliest abnormality detected in T2DM which is the main contributing factor for whole body insulin resistance (11). Despite several genetic and acquired defects of insulin action at receptor levels being studied in research, exact pathophysiology of muscle insulin resistance is yet to be identified. However when separation of the contributions of muscle and liver were studied, early improvement in the 
control of fasting plasma glucose level was shown to be associated predominantly with the improvement of liver insulin sensitivity $(12,13)$.

Additionally many individuals are observed to maintain normal blood glucose levels despite having similar levels of muscle insulin resistance to those with type 2 diabetes (14). Nevertheless, it has been recognised that longstanding muscle insulin resistance causes increase plasma insulin levels accelerating the accumulation of fat in the liver by stimulating de novo lipogenesis. Thus pathophysiological importance of muscle insulin resistance operates over a period of many years (1).

\section{Insulin resistance in the liver}

When daily caloric intake exceeds expenditure, storage of liver fat occurs increasing the metabolic stress to hepatocytes. Within the hepatocyte, fatty acids can be derived from de novo lipogenesis, uptake of non-esterified fatty acids and low density lipoproteins (LDL) or lipolysis of intracellular triacylglycerol. This fatty acid pool may be oxidized for energy production or may be combined with glycerol to form mono-, di-, or triacylglycerols (15). Chronic hyperinsulinaemia associated with long standing muscle insulin resistance accelerates de novo lipogenesis and production of malonyl-CoA which inhibits transport of fatty acids into mitochondria for oxidation. Thus newly synthesized triacylglycerol is preferentially directed towards storage or export, thereby increasing the hepatic fat content and plasma VLDL triacylglycerol levels (15). Furthermore, excess diacylglycerol profoundly affects the signalling pathway from insulin receptor to insulin receptor substrate 1 (IRS-1) which is the first post receptor step in intracellular insulin action causing insulin resistance (16). Additionally excess fatty acids promote ceramide synthesis which in turn increases gluconeogenic enzymes leading to increased hepatic glucose production (17). Thus, under circumstances of chronic energy excess, a raised level of intracellular diacylglycerol specifically prevents normal insulin action, and hepatic glucose production fails to be suppressed leading to increased fasting plasma glucose (1). Nevertheless, despite the above mentioned close relationship between raised liver fat content and insulin resistance, high levels of liver fat are not inevitably associated with hepatic insulin resistance in all individuals due to yet unidentified mechanisms (1).

\section{Beta cell dysfunction}

A population-based survey conducted in Mexico involving 2279 adults studied whether conversion of normoglycaemia to hyperglycaemia occurs gradually overtime or in a stepwise manner when diabetes develops. Very often the onset of diabetes was observed to be rapid, rather than gradual and it was in part explained by a fall in glucose- stimulated acute insulin response which plays a major role in determining glucose tolerance status over time (18). Furthermore, the progressive decrease in beta cell insulin secretion particularly in the first phase (acute insulin response) is likely the most critical functional defect in the development of T2DM according to physiological studies $(19,20)$. Moreover, subsequent studies revealed younger age and weight gain were more associated with diabetes progression from the onset (21) and around 50\% experienced loss of glycaemic control while on medications indicating unabated deterioration of beta cell function despite therapy (2).

\section{Pathophysiology of beta cell dysfunction}

In a background of long standing insulin resistance, pancreatic beta cells increase the output of insulin from each cell and/or increase its cell mass, to maintain normoglycaemia (22). Over a period of time inadequate compensation featured by inadequate insulin secretion from each cell or an inadequate beta cell mass for the levels of prevailing insulin sensitivity would lead to development of diabetes. The beta cell dysfunction is progressive and is usually considered to be about $50 \%$ by the time a person's plasma glucose level is in diabetic range. (22). Moreover it continues to worsen even after the development of diabetes.

Glucotoxicity and lipotoxicity are two acquired defects hypothesized to be associated with impaired insulin secretion. In glucotoxicity, chronic hyperglycaemia depletes insulin secretary granules from beta cells impairing the amount of insulin available for secretion. Furthermore, lowering of glucose levels has shown to improve acute beta cell insulin response (22). Lipotoxicity is characterised by reduced beta cell capacity due to chronic exposure to high level of fatty acids $(22,23)$. In a state of increased fatty acid levels beta cells avidly import them in to cells through CD 36 transporters and excess is stored as triglycerol. The energy surplus state prevents the increase in ATP production from the glucose oxidation which is a requirement for insulin secretion in response to glycaemic load. Additionally, increased fatty acid availability inhibits pyruvate cycling and the major rate-limiting enzyme of glucose oxidation the pyruvate dehydrogenase activity. Furthermore, in vitro studies have shown that excess fatty acids prevent beta cell proliferation by induction of cell cycle inhibitors P16 and P18, which is further worsened by high glucose concentration $(22,24,25$, and 26).

There is approximately $50 \%$ reduction in the number of beta cells in T2DM patients when compared to normoglycaemic subjects indicating reduction of total possible insulin response (22). Beta cell loss via apoptosis appears to increase as the duration of diabetes increases. The apoptosis is thought to be increased by chronic exposure to high concentration of fatty acid metabolites and products synthesised from fatty acids, such as ceramide $(27,28)$.

Low grade beta cell inflammation is hypothesised to be a possible contributory factor in the development of T2DM. Pancreatic islets from T2DM patients are known to have amyloid deposits, fibrosis, and increased cell death, associated with an inflammatory response. Glucotoxicity is a likely inducer of this inflammatory reaction (22). However, the onset and expression of hyperglycaemia is not uniform 
even in the presence of above mentioned pathological abnormalities indicating that individual susceptibility factors determine the onset of the condition, and both genetic and epigenetic factors may contribute $(1,22)$.

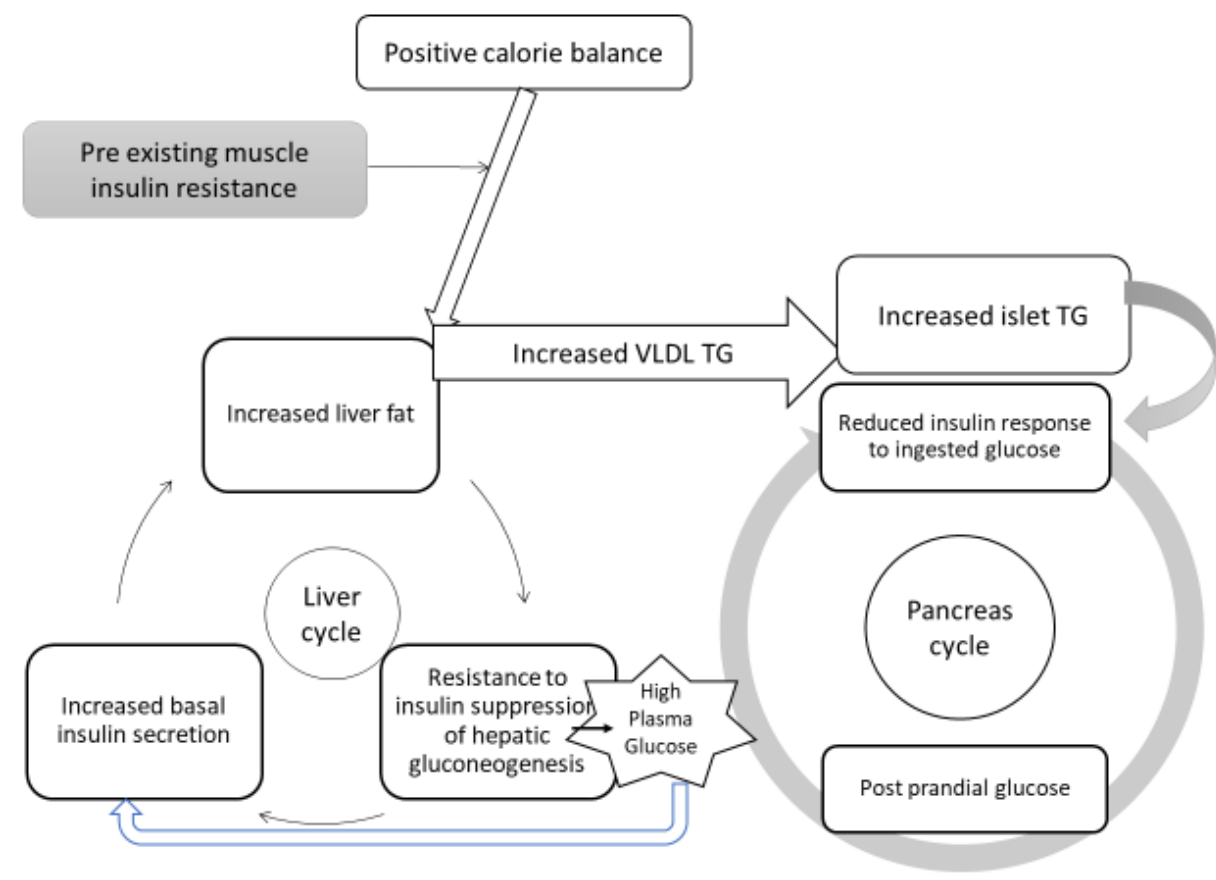

Figure 1: The twin cycle hypothesis of the aetiology of T2DM -adapted from Taylor R, 2013 (01)

\section{The twin cycle hypothesis of type 2 diabetes}

Evidence coming from bariatric surgery and hypocaloric diet has led to development of twin cycle hypothesis for aetiology of diabetes. Positive caloric balance is the primary influence of the whole process which leads to accumulation of liver fat and secondarily in the pancreas. These selfreinforcing cycles interact to bring about T2DM. Fatty liver leads to impaired fasting glucose metabolism and increases export of VLDL triacylglycerol, which increases fat delivery to all tissues, including the islets of pancreas. The liver and pancreas cycles drive forward even after onset of diabetes with steady decrease in beta cell function $(1,29)$.

\section{Is reversal of type 2 diabetes possible?}

Numerous studies conducted in the field of diabetes in search of a cure have revealed promising evidence on the possibility of reversal or remission of T2DM. Out of all the strategies used, most beneficial results were found with use of bariatric surgery and hypocaloric diet (1).

\section{Bariatric surgery}

Early indications of the possibility of T2DM being a fully reversible disease in some patients emerged from the outcomes of bariatric surgery (30-32). Bariatric surgery leads to remission of diabetes in up to $95 \%$ of patients. A randomised controlled trial (RCT) of 60 people comparing gastric bypass or bilio-pancreatic diversion and medical treatment revealed a remission rates of diabetes in $37 \%$ and $63 \%$ of patients respectively at 5 years, where none of the medically managed patients achieved remission (30). Adjustable gastric banding in diabetic patients diagnosed within 2 years with BMI between $30-40 \mathrm{~kg} / \mathrm{m}^{2}$, showed a remission rate of $73 \%$ at 2 years (31). Roux-en-Y gastric bypass (RYGB) was found to be more potent in achieving partial or complete remission of diabetes at 1 year, compared to adjustable gastric banding (32). The effect of normalization of blood glucose was persistent in almost $90 \%$ of patients even after 10 years of surgery (32).

\section{Dietary intervention}

The unforeseen observation of normalisation of blood glucose within days of bariatric surgery even before substantial loss of weight occur directed towards the possibility of acute profound decrease in caloric intake in reversing diabetes. There are several types of diet regimes studied in this purpose.

\section{Low calorie diet}

Studies have shown that remission of diabetes is achievable with low caloric diet. A study by Lim et al, where a 600 $\mathrm{kcal} /$ day diet comprising of liquid formulas and non-starchy vegetables for 8 weeks was given to 11 participants with a diabetes duration less than 4 years, shown significant reduction in FBS, along with improved insulin sensitivity in 
the liver, reduced liver and pancreatic fat content and improved beta cell function at 8 weeks (33).

An almost similar method was used by Steven et al, where very low calorie diet $(624 \mathrm{kcal} /$ day $)$ was given for 8 weeks, to patients with diabetes duration less than 8 years, followed by 2 week of isocaloric food reintroduction and followed up for 6 months of weight maintenance. $43 \%$ had remission of diabetes at the end of 6 months, and the remission negatively correlated with the duration of diabetes, baseline FBS and $\mathrm{HbA1}$, but no association was found with the baseline BMI (34).

\section{Intensive life style intervention}

In the Look AHEAD study involving around 5000, overweight adults with T2DM, where intensive lifestyle intervention (ILI) was compared to diabetes support and education programme (DSE), a frequent, weekly individual counselling was offered to the ILI group for the first 6 months followed by 3 per month for second 6 months and twice monthly for next 2 years. The ILI aimed to reduce total caloric intake to 1200 to $1800 \mathrm{kcal} / \mathrm{d}$ through reductions in total and saturated fat intake and by increasing physical activity levels to a goal of $175 \mathrm{~min} / \mathrm{wk}$. The remission rate was higher in ILI compared to DSE group, but however even in the ILI group the prevalence of remission was found to be low. Mean reduction of body weight of about $9 \%$ after one year in the intensive lifestyle intervention arm, was associated with a complete remission of only $1.3 \%$ of participants (35).

A retrospective study among 88 participants included in the Why WAIT, a 12 week multidisciplinary intensive weight management programme involving intensive and interactive medication adjustments, structured modified dietary intervention, graded exercise and cognitive behavioural programme, marked improvement in glycemic control was seen in 19 , with partial and complete remission in $2.3 \%$ each (36).

Recently, an open label, cluster -randomised trial- DiRECT, showed that remission of T2DM is a practical target in primary care with intensive weight management. All antidiabetic and anti-hypertensive medications were withdrawn in the intervention group at the beginning of the study, and a total diet replacement of nearly $850 \mathrm{kcal} /$ day was given followed by a stepped food reintroduction and weight management programme, targeting a weight loss of $15 \mathrm{~kg}$. The weight loss of $15 \mathrm{~kg}$ was achieved in $24 \%$ of the intervention group, $48 \%$ of intervention group achieved remission at 1 year (37)

Mediterranean diet

A randomized control trial, comparing a low carbohydrate Mediterranean diet (MED) to a low fat diet, in newly diagnosed patients with diabetes with BMI greater than 25 , showed that MED diet was associated with lower HbA1c and FBS, and lower need for initiation of drug treatment (38).

\section{Pharmacological interventions}

Oral hypoglycaemic agents and insulin alone, or in combination were studied with regard to their potential in reversing diabetes. Early Intensive insulin therapy appears to be promising when compared to oral hypoglycaemic agents in achieving diabetes remission.

\section{Oral hypoglycaemic agents}

Gliclazide MR $60 \mathrm{mg}$ was studied vs $16 \mathrm{u}$ of premixed insulin, in newly diagnosed drug naive diabetes patients with FBS $>200 \mathrm{mgs}$, along with medical nutrition therapy. Although blood glucose levels normalised in both groups in 2-6 weeks, the drug free remission with oral gliclazide was only $3 \%$ at 6 months, whereas in the insulin treated group it was $80 \%(39)$.

Oral hypoglycaemic agents(OHA) (glimepiride and /or metformin) vs. insulin glargine alone or in combination with above OHAs is used to achieve a FBS target of $6.1 \mathrm{mmol} / 1$, and 2-hr post meal glucose of $8 \mathrm{mmol} / \mathrm{l}$, which was maintained for 3 months, and after which the treatment was stopped. The remission rate was higher in the combination group (insulin + OHA) rather than OHA group at 1 year (40)

When taking everything into account, oral hypoglycaemic agents alone, has poor capacity to induce remission of diabetes when compared to insulin regimes.

\section{Insulin}

It was 30 years ago, a group of researchers showed that insulin treatment in NIDDM appears to have a beneficial effect by lowering insulin resistance, and resulted in remission of diabetes (41).

When insulin was given as a continuous subcutaneous infusion, in a physiological dose $(0.6 \mathrm{u} / \mathrm{kg}$ ) for 2 weeks, to achieve normoglycemia in a group of newly diagnosed diabetic patients who failed to achieve normoglycemia with diet and exercise, remission of diabetes was noted in 9 out 13 patients at 6 months (42).

Similarly Li et all demonstrated remission of diabetes along with the improvement in beta cell function in a group of newly diagnosed diabetes patients in a Chinese population treated with continuous subcutaneous insulin infusion for 2 weeks(43)

\section{Combination of interventions}

Combined diet and pharmacotherapy

Forty-two per cent of newly diagnosed, unselected African Americans with Type 2 diabetes, presenting with severe hyperglycaemia, treated intensively using pharmacological agents, education and diet developed near-norm glycaemic remission at 1 year (44). 
In a pilot study carried out among patients with diabetes diagnosed within 3 years and with a HbA1c of less than 8.5 while not on oral drugs or less than 7.5 in one or two OHA, a combination of lifestyle, OHAs (acarbose and metformin) or insulin glargine, either alone or in combination with OHAs was used for 8 weeks, and 16 weeks to achieve a target FBS of $4-5.3 \mathrm{mmol} / \mathrm{l}$ after which treatment was tailed off to zero over 5 days. Twelve weeks after completion of the intervention, $21.4 \%$ of the 8 week intervention group and $40.7 \%$ of the 16 week group met the HbA1c criteria for partial or complete diabetes remission (45)

Theories behind reversal of type 2 diabetes; what remission studies say?

The degree of weight loss stems the remission of diabetes in studies involving bariatric surgery. Since surgery is more effective in achieving weight loss, surgical procedures showed the most benefit when compared to non-surgical methods (30). Surgery induced specific changes mediated through incretin hormone secretion was thought to be the cause for immediate normalisation of blood sugar initially (46). But later on, acute profound reduction in calorie intake at the time of surgery was thought to be the more likely cause. This precipitous reversal of traffic in to fat stores brings about profound change in intracellular concentration of fat metabolites and other products synthesised from fatty acids (1).

Furthermore, in a state of negative calorie balance induced by surgery or diet, fat is mobilized first from the liver and other ectopic sites rather than from visceral or subcutaneous fat stores which ultimately leads to reduction of liver fat and improvement of hepatic insulin sensitivity (47). Thus fasting plasma glucose normalises within 7 days of the intervention (46). Moreover, normalisation of acute insulin response as well as the maximal insulin response can occur with substantial reduction of calorie intake over 8 weeks from similar interventions (11). Gradual and steady reduction of pancreatic fat content was compatible with the time course of the increase in both first phase and total insulin secretion in these studies.

According to the aforementioned understanding about beta cell apoptosis and rates of turnover during adult life, it is conceivable that removal of adverse factors such as glucotoxicity and lipotoxicity could result in restoration of normal beta cell number. Plasticity of lineage and transdifferentiation of human adult beta cells could possibly be contributing (48). All inclusively, it is clear that at least a critical mass of beta cells is not permanently damaged but merely metabolically stunned at the onset of T2DM. Thus induction of long lasting remission or reversal of T2DM is possible in some patients with right interventions more likely at the early period of the disease.

Paradigm shift in management of newly diagnosed patients with type 2 diabetes
Upcoming evidence on possibility of T2DM will change the face of the disease which was long known to have the nature of inevitable progression despite treatment. This evidence will give new hope to clinicians as well as patients who were labelled as having chronic illness which will ultimately cost their life span.

Though the approaches used to induce remission of type 2 diabetes look strenuous and laborious, the ultimate outcome will save a lifetime to the patient and a huge economical gain to the health care system if successful, by eliminating the long-term cost of medications and diabetic care.

Moreover even if the reversal is not achieved or not sustainable, the role of intensive glycemic control early in the course of the disease in preventing microvascular complications in the long run, is a well-established phenomenon. This concept is based on the hypothesis that microvascular complications are related to the degree and length of exposure to hyperglycaemia. This was described as "metabolic memory" by the DCCT/EDIC (49) investigators and as "legacy effect" by the UKPDS investigators (50).

\section{Metabolic memory /legacy effect}

Early achievement of glycaemic control translated into a long-term reduction of the risk of micro- and macro vascular complications in the UKPDS study. Despite an early loss of glycaemic differences between the conventional and intensive treatment group, a continued reduction in micro vascular risk and emergent risk reductions for myocardial infarction and death from any cause were observed during 10 years of post-trial follow-up (50) Similarly DCCT/EDIC follow-up study also demonstrated the legacy effect in type 1 diabetes in which the initial $2 \% \mathrm{HbA} 1 \mathrm{c}$ separation between the intensive or conventional control groups was lost during the follow up, when the two groups of participants returned to standard treatment but the initial intensively treated group continued to have lower rates of development of micro vascular and macro vascular complications. (49). The underlying mechanism behind the metabolic memory or legacy effect is still not clearly elucidated.

With the available evidence, it can be assumed, regardless of the reintroduction or escalation of medications after the intensive treatment phase, and glycaemic control after the cessation of intensive glycemic management, the long-term cardiovascular outcomes should be better in the intensively managed patients. However, long term follow up of the regression trials are necessary to study the phenomenon of metabolic memory or legacy effects in the study population treated with intensive glycemic control.

\section{Limitations of the regression studies}

Though there are multiple approaches to induce regression of T2DM, except for bariatric surgery and hypocaloric diet, other approaches were not uniformly studied. Furthermore those approaches are not comparable to each other because of the different study population with regard to BMI, 
duration of diabetes and baseline HbA1c. In addition, the definition of remission varies between trials. Most of the data available on the regression of diabetes is from overweight or obese subjects. Specially in an Asian population where lean diabetes/ diabetes with a normal BMI is prevalent(51), due to the presence of high visceral adiposity, the applicability of the above principles remain unknown and need to be evaluated.

Quality of life is an important domain to be assessed when major changes in lifestyle have been made. However there was no significant difference in quality of life between the intensive life style intervention arm and the control arm in one study (45). But subsequently the DiRECT trial demonstrated significant improvement in the quality of life at 12 months as measured by the EuroQol 5 Dimensions visual analogue scale (37). Adhering to an intensive lifestyle modification with regard to diet and exercise is challenging and need continuous motivation and support. But the aforementioned trials have proved that it is a practical target even in primary care set up.

Cardiovascular disease remains the main cause of mortality in diabetes, and it is of no wonder, that treatment modalities of diabetes mellitus should address the cardiovascular outcomes. Long term follow up data regarding the sustenance of remission, cardiovascular outcomes and diabetic related complications is sparse in the regression trials. Most of the studies have been done with a short term follow-up of 6 months to 1 year. A Chinese follow-up study over 20 years, after an intensive life style intervention of 6 years failed to show significant cardiovascular benefit compared to the control group(52).An 8 year follow-up of LOOK AHEAD trial showed some optimism regarding the sustainability of weight loss over 8 years with ILI. Although the study showed benefits of the weight loss intervention on diverse outcomes, including chronic kidney disease, disability, depression, and sleep quality, no significant effect was demonstrated on CVD, raising the concerns regarding the benefits of life style interventions in long term (53).

The huge cost associated with above mentioned approaches is also an important issue when applying this concept in resource poor settings like in the Asian context, where $60 \%$ of world diabetic population live. Special dietary practices exercise programmes, medication cost and stringent monitoring during this process, add to the initial cost on management of the patient. Overcrowded health care centres and lack of experience regarding the above concept further pushes away the mission of achieving diabetes remission.

\section{Conclusion}

Remission of diabetes has become an achievable ambition using multiple approaches. The safety and sustainability of the interventions remains to be elucidated. Further multi cantered studies with long term follow up are needed, comparing different approaches in achieving long-term remission of diabetes and evaluating cardiovascular outcomes and complications.

\section{References}

1. Taylor R. Type 2 Diabetes. Diabetes Care. 2013 Apr 1;36(4):1047 -1055.

2. Turner, R.C, et al. Glycemic control with diet, sulfonylurea, metformin, or insulin in patients with type 2 diabetes mellitus: progressive requirement for multiple therapies (UKPDS 49) UK Prospective Diabetes Study (UKPDS) Group. JAMA. 1999;281(21): 2005-2012

3. Kahn SE, Haffner SM, Heise MA, Herman WH, Holman RR, Jones NP, et al. Glycemic Durability of Rosiglitazone, Metformin, or Glyburide Monotherapy. N Engl J Med. 2006;355(23):2427-43.

4. Cusi K, Maezono K, Osman A, Pendergrass M, Patti ME, Pratipanawatr T, et al. Insulin resistance differentially affects the PI 3-kinase- and MAP kinase-mediated signaling in human muscle. J Clin Invest. 2000;105(3):311-20.

5. Herman MA, Kahn BB. Glucose transport and sensing in the maintenance of glucose homeostasis and metabolic harmony. J Clin Invest. 2006;116:1767-1775

6. Roden M, Price TB, Perseghin G, Petersen KF, Rothman DL, Cline GW, et al. Mechanism of free fatty acid-induced insulin resistance in humans. J Clin Invest. 1996;97(12):2859-65.

7. Hull RL, Westermark GT, Westermark P, Kahn SE. Islet Amyloid: A Critical Entity in the Pathogenesis of Type 2 Diabetes. J Clin Endocrinol Metab. 2004;89(8):3629-43.

8. Roma LP, Pascal SM, Duprez J, Jonas J-C. Mitochondrial oxidative stress contributes differently to rat pancreatic islet cell apoptosis and insulin secretory defects after prolonged culture in a low non-stimulating glucose concentration. Diabetologia. 2012;55(8):2226-37.

9. CnopM. Fatty acids and glucolipotoxicity in the pathogenesis of Type 2 diabetes. Biochem Soc Trans. 2008;36:348-352

10. Ahrén B, Gomis R, Standl E, Mills D, Schweizer A. Twelve- and 52-Week Efficacy of the Dipeptidyl Peptidase IV Inhibitor LAF237 in Metformin-Treated Patients With Type 2 Diabetes. Diabetes Care. 2004;27(12):2874 LP-2880. 
11. Petersen KF, Dufour S, Morino K, Yoo PS, Cline GW, Shulman GI. Reversal of muscle insulin resistance by weight reduction in young, lean, insulin-resistant offspring of parents with type 2 diabetes. Proc Natl Acad Sci U S A. 2012;109(21):8236-40.

12. Lim EL, Hollingsworth KG, Aribisala BS, Chen MJ, Mathers JC, Taylor R. Reversal of type 2 diabetes: Normalisation of beta cell function in association with decreased pancreas and liver triacylglycerol. Diabetologia. 2011;54(10): 38

13. Gastaldelli A, Cusi K, Pettiti M, Hardies J, Miyazaki Y, Berria R, et al. Relationship Between Hepatic/Viscerc Hepatic Insulin Resistance in Nondiabetic and Type 2 Diabetic Subjects. Gastroenterology. 2007;133(2):496-506.

14. Taylor R. Insulin resistance and type 2 diabetes. Diabetes 2012;61:778-779

15. Szendroedi J, Chmelik M, Schmid AI, Nowotny P, Brehm A, Krssak M, et al. Abnormal hepatic energy homeostasis in type 2 diabetes. Hepatology. 2009;50(4):1079-86.

16. Samuel VT, Petersen KF, Shulman GI. Lipid-induced insulin resistance: unravelling the mechanism. Lancet (London, England). 2010;375(9733):2267-77.

17. Kumashiro N, Erion DM, Zhang D, Kahn M, Beddow SA, Chu X, et al. Cellular mechanism of insulin resistance in nonalcoholic fatty liver disease. Proc Natl Acad Sci U S A. 2011/09/19. 2011;108(39):16381-5.

18. Ferrannini E, Nannipieri M, Williams K, Gonzales C, Haffner SM, Stern MP. Mode of Onset of Type 2 Diabetes from Normal or Impaired Glucose Tolerance. Diabetes. 2004;53(1):160 LP-165.

19. Weyer C, Tataranni PA, Bogardus C, Pratley RE. Insulin Resistance and Insulin Secretory Dysfunction Are Independent Predictors of Worsening of Glucose Tolerance During Each Stage of Type 2 Diabetes Development. Diabetes Care. 2001;24(1):89 LP-94.

20. Festa A, Williams K, D'Agostino R, Wagenknecht LE, Haffner SM. The Natural Course of $\beta$-Cell Function in Nondiabetic and Diabetic Individuals. Diabetes. 2006;55(4):1114 LP-1120.

21. Pani LN, Nathan DM, Grant RW. Clinical predictors of disease progression and medication initiation in untreated patients with type 2 diabetes and A1C less than 7\%. Diabetes Care. 2007/12/14. 2008 Mar;31(3):386-90.

22. Fonseca, V.A. Defining and Characterizing the Progression of Type 2 Diabetes. Diabetes care. 2009;32(2): S151-S156

23. Tushuizen ME, Bunck MC, Pouwels PJ, Bontemps S, van Waesberghe JHT, Schindhelm RK, et al. Pancreatic Fat Content and $\beta$-Cell Function in Men With and Without Type 2 Diabetes. Diabetes Care. 2007;30(11):2916 LP-2921.

24. Ravikumar B, Gerrard J, Dalla Man C, Firbank MJ, Lane A, English PT, et al. Pioglitazone decreases fasting and postprandial endogenous glucose production in proportion to decrease in hepatic triglyceride content. Diabetes. 2008;57(9):2288-95.

25. Noushmehr H, D’Amico E, Farilla L, Hui H, Wawrowsky KA, Mlynarski W, et al. Fatty Acid Translocase Is Localized on Insulin-Containing Granules in Human Pancreatic $\beta$-Cells and Mediates Fatty Acid Effects on Insulin Secretion. Diabetes. 2005;54(2):472 LP-481.

26. Diakogiannaki E, Dhayal S, Childs CE, Calder PC, Welters HJ, Morgan NG. Mechanisms involved in the cytotoxic and cytoprotective actions of saturated versus monounsaturated long-chain fatty acids in pancreatic beta-cells. J Endocrinol. 2007;194(2):283-91.

27. Shimabukuro M, Higa M, Zhou Y-T, Wang M-Y, Newgard CB, Unger RH. Lipoapoptosis in Beta-cells of Obese Prediabeticfa/fa Rats: ROLE OF SERINE PALMITOYLTRANSFERASE OVEREXPRESSION . J Biol Chem . 1998;273(49):32487-90.

28. Shimabukuro M, Zhou YT, Levi M, Unger RH. Fatty acid-induced beta cell apoptosis: a link between obesity and diabetes. Proc Natl Acad Sci U S A. 1998 Mar 3;95(5):2498-502.

29. Taylor R. Pathogenesis of type 2 diabetes: tracing the reverse route from cure to cause. Diabetologia. 2008;51:1781-1789

30. Guidone C, Iaconelli A, Leccesi L, Nanni G, Pomp A, Castagneto M, et al. Bariatric Surgery versus Conventional Medical Therapy for Type 2 Diabetes. 2012;1577-85.

31. Dixon JB, O’Brien PE, Playfair J, Chapman L, Schachter LM, Skinner S, et al. Adjustable Gastric Banding and Conventional Therapy for Type 2 Diabetes. Jama. 2008;299(3).

32. Courcoulas AP, Goodpaster BH, Eagleton JK, Belle SH, Kalarchian MA, Lang W, et al. Surgical vs Medical Treatments for Type 2 Diabetes Mellitus: A Randomized Clinical TrialTreatment for Type 2 Diabetes MellitusTreatment for Type 2 Diabetes Mellitus. JAMA Surg. 2014 Jul 1;149(7):707-15..

33. Lim EL, Hollingsworth KG, Aribisala BS, Chen MJ, Mathers JC, Taylor R. Reversal of type 2 diabetes: Normalisation of beta cell function in association with decreased pancreas and liver triacylglycerol. Diabetologia. 2011;54(10):2506-14.

34. Steven S, Hollingsworth KG, Al-Mrabeh A, Avery L, Aribisala B, Caslake M, et al. Very low-calorie diet and 6 months of weight stability in type 2 diabetes: Pathophysiological changes in responders and nonresponders. Diabetes Care. 2016;39(5):808-15..

35. Gregg EW, Chen H, Wagenknecht LE, Clark JM, Delahanty LM, Bantle J, et al. Association of an Intensive Lifestyle Intervention. 2013;308(23):2489-96.

36. Mottalib A, Sakr M, Shehabeldin M, Hamdy O. Diabetes Remission after Nonsurgical Intensive Lifestyle Intervention in Obese Patients with Type 2 Diabetes. J Diabetes Res. 2015;2015:1-4.

37. Lean MEJ, Leslie WS, Barnes AC, Brosnahan N, Thom G, Mccombie L, et al. Articles Primary care-led weight management for remission of type 2 diabetes ( DiRECT ): an open-label, cluster-randomised trial. Lancet. 2018;391(10120):541-51. 
38. Esposito K, Maiorino MI, Petrizzo M, Bellastella G. The Effects of a Mediterranean Diet on the Need for Diabetes Drugs and Remission of Newly Diagnosed Type 2 Diabetes : Follow-up of a Randomized Trial. 2014; 37:1824-30

39. Chandra ST, Priya G, Khurana ML, Jyotsna VP, Sreenivas V, Dwivedi S, et al. Comparison of Gliclazide with Insulin as Initial Treatment Modality in Newly Diagnosed Type 2 Diabetes. Diabetes Technol Ther. 2008;10(5):363-8. . doi: 10.1089/dia.2008.0045.

40. Mu P, Chen Y, Lu H, Wen X, Zhang Y, Xie R, et al. Effects of a combination of oral anti-diabetes drugs with basal insulin therapy on $\beta$-cell function and glycaemic control in patients with newly diagnosed type 2 diabetes. Diabetes Metab Res Rev. 2012;28(3):236-40.

41. Samanta A, Burden AC, Jones GR, Clarkson L. The effect of short term intensive insulin therapy in non-insulindependent diabetics who had failed on sulphonylurea therapy. Diabetes Res. 1986 Jun;3(5):269—271.

42. Ilkova H, Glaser B, Tunçkale A, Bagriaçik N, Cerasi E. Induction of long-term glycemic control in newly diagnosed type 2 diabetic patients by transient intensive insulin treatment. Diabetes Care. 1997;20(9):1353-1356

43. Li Y, Xu W, Liao Z, Yao B, Chen X, Huang Z, et al. Induction of Long-term Glycemic Control in Newly Diagnosed Type 2 Diabetic. Diabetes Care. 2004;27(11):2597-602.

44. McFarlane SI, Chaiken RL, Hirsch S, Harrington P, Lebovitz HE, Banerji MA. Near-normoglycaemic remission in African-Americans with Type 2 diabetes mellitus is associated with recovery of beta cell function. Diabet Med. 2001;18(1):10-6.

45. Mcinnes N, Smith A, Otto R, Vandermey J, Punthakee Z, Sherifali D, et al. Piloting a Remission Strategy in Type 2 Diabetes: Results of a Randomized Controlled Trial. 2017;102:1596-605.

46. Guidone C, Manco M, Valera-Mora E, Iaconelli A, Gniuli D, Mari A, et al. Mechanisms of Recovery From Type 2 Diabetes After Malabsorptive Bariatric Surgery. Diabetes. 2006 Jul 1;55(7):2025 LP-2031.

47. Colles SL, Dixon JB, Marks P, Strauss BJ, O’Brien PE. Preoperative weight loss with a very-low-energy diet: quantitation of changes in liver and abdominal fat by serial imaging. Am J Clin Nutr2006;84:304-311

48. Szabat M, Lynn FC, Hoffman BG, Kieffer TJ, Allan DW, Johnson JD. Maintenance of $\beta$-cell maturity and plasticity in the adult pancreas: developmental biology concepts in adult physiology. Diabetes2012;61:1365-1371

49. Diabetes Control and Complications Trial (DCCT)/Epidemiology of Diabetes Interventions and Complications (EDIC) Study Research Group. Intensive diabetes treatment and cardiovascular outcomes in type 1 diabetes: The DCCT/EDIC study 30-year follow-up. Diabetes Care. 2016; 39: 686-693

50. Holman RR, Paul SK, Bethel MA, Matthews DR, Neil HAW. 10-Year Follow-up of Intensive Glucose Control in Type 2 Diabetes. N Engl J Med. 2008 Oct 9;359(15):1577-89.

51. Chan JCN, Yeung R, Luk A. The Asian diabetes phenotypes: Challenges and opportunities. Diabetes Res Clin Pract. 2014;105(1):135-9.

52. Li G, Zhang P, Wang J, Gregg EW, Yang W, Gong Q, Li H, Li H, Jiang Y, An Y, Shuai Y, Zhang B, Zhang J, Thompson TJ, Gerzoff RB, Roglic G, Hu Y, Bennett PH. The long-term effect of lifestyle interventions to prevent diabetes in the China Da Qing Diabetes Prevention Study: a 20-year follow-up study. Lancet. 2008;371(9626):1783-9. doi: 10.1016/S0140-6736(08)60766-7.

53. Look AHEAD Research Group. Cardiovascular Effects of Intensive Lifestyle Intervention in Type 2 Diabetes. N Engl J Med. 2013 Jun 24;369(2):145-54. 